SHORT COMMUNICATION

\title{
Influence of dietary condition on the ratio of the compounds emitted by larvae Chilecomadia valdiviana (Lepidoptera: Cossidae)
}

\author{
Luis J. Reyes-García ${ }^{1, *}$ (D); María José Muñoz ${ }^{1}$; Pamela Cuevas $^{2}$ (D) \\ 1 Departamento de Ciencias Básicas, Facultad de Ciencias, Universidad Santo Tomás, Chile. \\ 2 Escuela de Tecnología Médica, Universidad Santo Tomás, Limonares 190, Viña del Mar, Chile.
}

Received February 8, 2020. Accepted May 22, 2020.

\begin{abstract}
Chilecomadia valdiviana (Lepidoptera, Cossidae), locally known as "Gusano del Tebo", is a polyphagous pest that, in its larval stage, feeds on the wood of the host species. $C$. valdiviana is distributed in the southern region of Chile and Argentina and its larvae mainly attack eucalyptus and fruit trees. Previous research has reported the identification of the volatile compounds produced by this species in its larval stage. In this work, the effects of two dietary conditions on these volatile compounds were described: groups of individuals fed with wood vs. others without food. The results obtained provide empirical evidence that $C$. valdiviana modulates the emission of the compounds according to the effect of stimulus.

Keywords: volatile emission; Tebo worm; Chilecomadia valdiviana; dietary condition.
\end{abstract}

\section{Introduction}

Chilecomadia valdivian (Philippi) (Lepidoptera, Cossidae) is a polyphagous insect native to Chile that is associated with Eucalyptus nitens, Nothofagus antarctica, Nothofagus dombey, as well as other fruit species with economic importance for Chile, such as avocados, apple trees, olives, and pears (Herrera et al., 2016). The larva forms numerous galleries in the host species, with diameters of between 10 and $12 \mathrm{~mm}$, producing a large amount of sawdust and debris. These consequences, the action of woodpeckers and the entrance of organisms such as fungi, ultimately cause rotting of the wood (Ramos-González, 2017). There is little clarity about the life cycle of this species, but this has been estimated at between 1 and 3 years (Urra, 2016).

This insect produces a series of volatile compounds (short-chain acetates, saturated and unsaturated) that, in previous studies, were identified in larval hexane extracts. The major compounds found were (Z)-5,13-tetradecadienyl acetate, dodecyl acetate, and (Z)-5-Tetradecenyl acetate, with relative abundances of $44 \%, 37 \%$, and $14 \%$, respectively (Bergmann et al., 2007). There is no consensus about the biological activity of these compounds. However, empirical evidence suggests that the acetate compound of (Z)-5,13-tetradecadienyl could act as an aggregation pheromone (Reyes-García et al., 2011). This work aimed to study the effects of two dietary conditions: groups of individuals fed with wood vs. others without food. Based on the results of the feeding performance assay, we further hypothesized that the nutritional status of the larva (starved vs. nonstarved larvae) affects the ratio of the volatile compounds emitted by the insect. No previous reports are describing this behavior in larvae.

\section{Materials and methods}

2.1 Insects. Larvae of $C$. valdiviana were purchased in fishing equipment stores in Quilpué and were identified according to the morphological characteristics described by Olivares and Angulo (1992).

Cite this article:

Reyes-García, L.J; Muñoz, M.J.; Cuevas, P. 2020. Influence of dietary condition on the ratio of the compounds emitted by larvae Chilecomadia valdiviana (Lepidoptera: Cossidae). Scientia Agropecuaria 11(2): 233 - 236. 
2.2 Extracts. The crude extract of larvae was prepared by maceration according to Teh et al., (2017). For the analyzes of the studied treatments, larvae were taken at 24,48 , and $72 \mathrm{~h}$.

2.3 Collection of volatiles. Larvae in their last stage were kept under controlled conditions $\left(25 \pm 2^{\circ} \mathrm{C}, 40 \%\right.$ relative humidity, photoperiod L16: D8); ten individuals were placed in each of two 2.5-L glass bottles conditioned as aeration chambers (Vera et al., 2016). Teflon tubes were used. Eucalyptus wood was used to feed the larvae. Air purified by activated charcoal (50-200 mesh, Fisher Scientific Company, Pittsburgh, PA) was passed through the chamber at a flow of approximately $2.5 \mathrm{~L}$ $\mathrm{min}^{-1}$. Volatiles were adsorbed on $200 \mathrm{mg}$ of activated charcoal (50-200 mesh, Fisher Scientific Company, Pittsburgh, PA), which was placed in a glass tube $(4 \mathrm{~mm}$ in diameter and $5 \mathrm{~cm}$ long). Glass wool was used to fix the charcoal in the tube. Samples were taken after 24, 48, and $72 \mathrm{~h}$ from the beginning of the experiment. The adsorbed volatiles was eluted with $1.5 \mathrm{~mL}$ of hexane (Suprasolv, Merck). The samples were concentrated using a gentle flow of nitrogen. Samples were stored in screw cap vials at $-20^{\circ} \mathrm{C}$ until further analysis.

2.4 Chemical analysis. The analysis by gas chromatography was carried out using a Shimadzu equipment (Shimadzu, GC-2010 Plus, Kyoto, Japan), which was equipped with a flame ionization detector (FID), and a fused silica RTX-Wax capillary column RTX was used $(30 \mathrm{~m} \times 0.25 \mathrm{~mm} \mathrm{RTX} \Omega-5$ film, Restek, Bellefonte, PA, USA). This was programmed as follows: from $60^{\circ} \mathrm{C}$ for $5 \mathrm{~min}$ up to $220{ }^{\circ} \mathrm{C}$ at $10{ }^{\circ} \mathrm{C} \mathrm{min-1}$. The gas chromatograph was operated in splitless

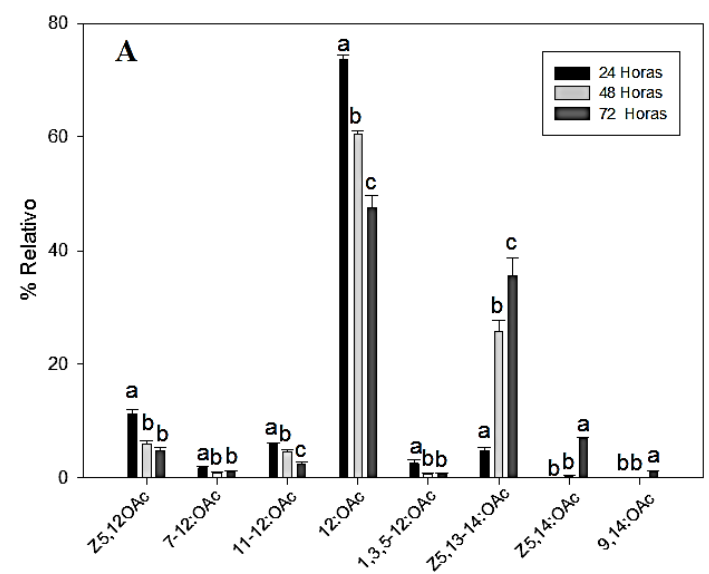

mode with an injector temperature of $250^{\circ} \mathrm{C}$. Helium was used as a carrier gas.

The GC-MS analysis was performed with a Shimadzu team (Shimadzu, GCMS-QP2010 Ultra, Kyoto, Japan), using an RTX-5 column, and was programmed in a similar way to that described in the previous paragraph. The mass spectrum was acquired at $70 \mathrm{eV}$, and Helium was used as the carrier gas.

2.5 Statistic analysis. The relative percentage of each compound was determined in triplicate and analyzed by analysis of variance (ANOVA), followed by the Tukey test $(p \leq 0.05)$, using the XLSTAT program (2009).

\section{Results and discussion}

In the treatment of wood-fed larvae, a gradual decrease (every $24 \mathrm{~h}$ ) in the emission of compounds generated by the larva was detect, including (Z)-5-dodecenyl acetate (Z5-12:OAc), 7-dodecenyl acetate (7-12:OAc), 11-tetradecenyl acetate (1112:OAc), and dodecyl acetate (12:OAc). About the compounds of (Z)-5,13tetradecadienyl acetate (Z5,13-14:OAc) and (Z)-5-tetradecenyl acetate (Z5,14:OAC), an increasing trend in the emission was detected (Fig. 1A). These compounds were detected in a greater proportion. In this experiment, the compounds 13-tetradecenyl acetate $(13,14: O A c)$ and tetradecyl acetate (14:OAc) were not detected. The ratio of compounds present in the larva was determined by the realization of hexane extracts, as described by Bergmann et al. (2007), a study that described only the percentage of compounds in the hexane extract, and in which variation in the emission of volatiles, overtime was not described.

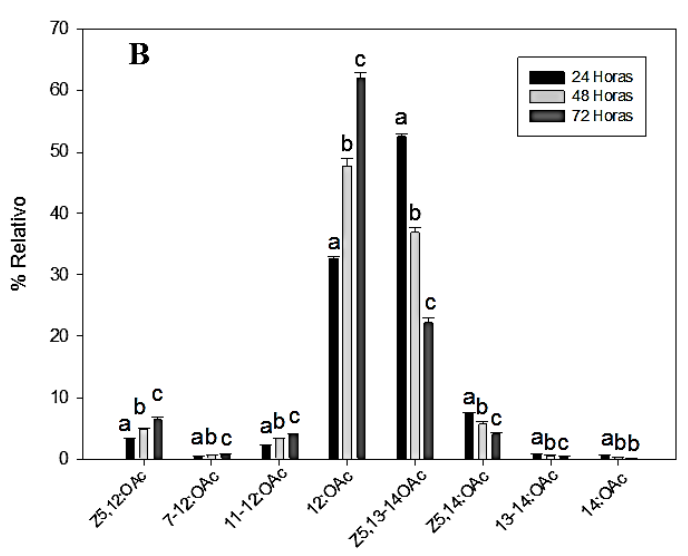

Figure 1. The relative percentage of volatiles emitted by larvae of $C$. Valdiviana; A: feeding with wood and B: no feed. Statistical analysis was performed-by-compound. The values followed by different letters are statistically different ( $p<$ 0.05 according to ANOVA followed by the Tukey-Kramer test). 
About the experiment where the larva was kept without food, an increase in the emissions of compounds Z5-12:OAc, 712:OAc, 11-12:OAc, and 12:OAc was increase; this effect is opposite to that detected in the species fed. On the other hand, the compounds $25,13-14: O A c$ and Z5,14:OAc showed a decreasing emission (Fig. 1B), which is opposite to the results of the first experiment (Fig. 1A). In this experiment, the compounds 9-tetradecenyl acetate $(9,14: \mathrm{OAC})$ and tetradecatrienyl acetate $(1,3,5-12: O A c)$ were not detected. Thus, the emission of these volatile compounds differs according to the stimulus over the insect is subjected, while the percentage of compounds found in extracts made by maceration of the larva was similar under the two tested conditions. The compounds produced by the larva of the C. Valdiviana species have been found in other adult specimens of species belonging to the lepidopteran order and have various reported biological activities. Thus, Z512:OAc, 7-12:OAc, and 11-12:OAc act mainly as pheromones of sexual attraction in adult specimens (Zhang et al., 2016; Chynoweth et al., 2018; Williams et al., 2019; Fu-cun et al., 2017). On the other hand, 12:OAc has been reported in larvae of the species C. morei, Cossus cossus, and Zeuzera pyrina. 12:OAc is also present in species of the order Hymenoptera, in which this compound has been reported as an alarm pheromone (De Bruijin et al., 2016; Von Zuben et al., 2016). In the case of the insect Frankliniella occidentalis, 12:OAc works as a defense against several predators and is produced quickly after an attack. Thus, it is assumed that this behavior facilitates its survival. On the other hand, the compound Z5,13-14:OAC has been identified in other larvae of the Cossus cossus family (Capizzi et al., 1983) although the function of this compound is unknown, it was reported that, for the species $C$. valdiviana, $\mathrm{Z} 5,13-14: \mathrm{OAc}$ acts as an aggregation pheromone (Reyes-García et al., 2011).

Several studies demonstrate the role of diet quality for mate assessment pheromones across a wide range of taxa, including insects (Baruffaldi and Andrade, 2015).

There are two mechanisms in which the relationship of mixtures of pheromonal components can vary, the first mechanism involves small gradual changes of the components, where the species stops emitting a compound or changes the relationship, while the second method involves a "saltational" change in which the changes generate a large or completely different phenotype from the ancestor (Henneken et al., 2017; Baker, 2002). For example, in the case of the species Trichoplusia ni (Lepidóptera, Noctuidae), the female moth can change the ratio of compounds emitted due to a mutation of the gene responsible for the production of pheromones, a change that is permanent and represents a reproductive disadvantage since this new mixture of compounds is not recognized by the males of this species (Allison, 2016). In other cases, dietmediated variation in the signal may provide indirect information about the signaller's genotype, such as the genes responsible for an individual's foraging ability (Henneken et al., 2017).

In the case of the specific object of this study, the change in the ratio of compounds emitted is not permanent and can be associated with epigenetic factors. In this sense, the fact that the production of $Z 5,13$ 14:OAc increases and the emission of 12:OAc decreases (in the situation where the larvae are maintained with food), would indicate an alert to other individuals of their species about the availability of food and absence of threats, which would be a condition of the oviposition site of adult females. Moreover, diet-related variation in chemical cues emanating from predators can be used by prey as cues revealing the presence of predators (Sharp et al., 2015). In this way, the tendency of this species to re-infest the trees already attacked in the previous season could be explained, as well as the presence of many larvae in the same host. On the other hand, when the larva remains without food, the fact that the production of Z5,13-14:OAc decreases and the emission of 12:OAc gradually increases would alert individuals about the absence of food, discouraging infestation of this sector. The results of this study could be explained through epigenetic mechanisms, which are conditioned by the environment in which the species is found. Epigenetic modifications can change the expression of genes associated with the biosynthesis of these compounds (Antony et al., 2016; Benayoung et al., 2015), thus representing the complex chemical communication system dependent on environmental variations.

\section{Conclusions}

According to the results obtained, it can be concluded that larvae under different dietary conditions (fed with wood and without food), showed specific differences in the volatiles emitted. Over the study's period, there was a gradual change in the ratio of the fatty acid derivatives emitted by 
the C. Valdiviana larva. This study is the first report describing the behavior of these larvae about feeding. The evidence that dietary conditions can influence the volatiles emitted by larvae suggests that this information should be considered in the designing of experiments in similar studies.

\section{Acknowledgments}

The authors acknowledge the financial support of the Vice-Rectorate of Research and Postgraduate of the University Santo Tomas (project code TAS o000022497).

\section{ORCID}

L. Reyes-García (D) https:/lorcid.org/0000-0002-7224-3226

M.J. Muñoz (D) https://orcid.org/0000-0003-2318-0684

P. Cuevas (D) https://orcid.org/0000-0002-5611-1688

\section{References}

Allison, J. 2016. Pheromone Communication in Moths: Evolution, Behavior, and Application. Editorial University California Press. Oakland, California, USA.

Antony, B.; Ding, B.; Moto, K.; et al. 2016. Two fatty acyl reductases involved in moth pheromone biosynthesis. Scientific Reports 6: 29927.

Baker, T.C. 2002. Mechanism for saltational shifts in pheromone communication systems. Proceedings of the National Academy of Sciences 99: 13368-13370

Baruffaldi, L.; Andrade, M. 2015. Contact pheromones mediate male preference in black widow spiders: avoidance of hungry sexual cannibals? Animal Behavior 102: 25-32.

Benayoun, B.; Pollina, E.; Brunet, A. 2015. Epigenetic regulation of ageing: linking environmental inputs to genomic stability. Nature Reviews Molecular Cell Biology 16: 593-610.

Bergmann, J.; Lopez, K.; Buono-Core, G. 2007. Identification and synthesis of some fatty acio derivatives from larvae of Chilecomadia valdiviana (Lepidoptera: Cossidae). Natural Product Research 21: 473-480.

Capizzi, A.; Tonini, E.; Arsura, G.; et al. 1983. Sex pheromone components of the European goat moth, Cossus cossus. Journal of Chemical Ecology 9(2): 191-200.

Chynoweth, R.; Rolston, P.; McNeill, M.; et al. 2018. Red clover casebearer moth (Coleophora deauratella) is widespread throughout New Zealand. New Zealand Plant Protection 71: 232-239.
De Bruijn, P.; Egas, M.; Sabelis, W.; et al. 2016. Contextdependent alarm signalling in an insect. Journal of Evolutionary Biology 29(3): 665-671.

Fu-cun, S.; Xiang-bo, K.; Su-fang, Z.; et al. 2017. Geographic Variation of Sex Pheromones in Three Populations of Dendrolimus kikuchii (Lepidoptera: Lasiocampidae). Forest Research 30(6): 993-998.

Henneken, J.; Goodger, J.; Jones, T.; et al. 2017. DietMediated Pheromones and Signature Mixtures Can Enforce Signal Reliability. Frontiers in Ecology and Evolution 4: 145.

Herrera, H.; Barros-Parada, W.; Flores, M.; et al. 2016. Identification of a Novel Moth Sex Pheromone Component from Chilecomadia valdiviana. Journal of Chemical Ecology 42: 908-918.

Olivares, T. and Angulo, A. 1992. Chilecomadia valdiviana (Philippi): descripción de larva y pupa. (Lepidoptera: Cossidae). Gayana Zoología 56: 181-184.

Ramos-González, M. 2017. Las mariposas (Insecta: Lepidoptera) depositadas en el Museo de Historia Natural de Concepción, Chile. Colecciones Digitales, Subdirección de Investigación DIBAM. 1-27.

Reyes-García, L.; Flores, M.; Vera, W.; et al. 2011. Biological activity of the larval secretion of Chilecomadia valdiviana. Journal of Chemical Ecology 37: 1137-1142.

Sharp, J.; Garnick, S.; Elgar, M.; et al. 2015. Parasite and predator risk assessment: nuanced use of olfactory cues. Proceedings of the Royal Society B: Biological Sciences 282: 1-5.

Teh, C.; Nazni, W.; Nurulhusna, A.; et al. 2017. Determination of antibacterial activity and minimum inhibitory concentration of larval extract of fly via resazurin-based turbidometric assay. BMC Microbiology 17: 1-8.

Urra, F. 2016. El gusano del tebo, la ansiada carnada. Available at: https://www.mnhn.gob.cl/613/w3article-73189.html?_noredirect=1

Vera, W.; Parra, L.; Quiroz, A.; et al. 2016. Attraction to host plant volatiles and feeding performance of Naupactus Xanthographus (Coleoptera: Curculionidae) is affected by starvation. Journal of Insect Behavior 29(1): 48-56.

Von Zuben, L.; Schorkopf, D.; Elias, L.; et al. 2016. Interspecific chemical communication in raids of the robber bee Lestrimelitta limao. Insectes Sociaux 63(2): 339-347.

Williams, L.; Serrano, J.; Johnson, P.; et al. 2019. 13Tetradecenyl acetate, a female-produced sex pheromone component of the economically important click beetle Melanotus communis (Gyllenhal) (Coleoptera: Elateridae) Scientific Reports 9: 16197.

Zhang, S.; Kong, X.; Ze, S.; et al. 2016. Discrimination of cis-trans sex pheromone components in two sympatric Lepidopteran species. Insect Biochemistry and Molecular Biology 73: 47-54. 